\title{
Perinatal depression and psychosis: an update
}

\author{
Myles Doyle, Angela Carballedo \& Veronica O'Keane
}

\begin{abstract}
SUMMARY
About $85 \%$ of women experience some type of postpartum mood disturbance. Generally, the symptoms are mild and short-lived, but a minority of women develop depressive illness or sudden psychosis. About half of episodes of apparently postnatal depression start during pregnancy and some seemingly postpartum psychoses start before delivery. Untreated antenatal depression can lead to poor obstetric outcomes, subsequent depression in the mother, and developmental disadvantage and depression later in life in the offspring. In this article we discuss the aetiology of perinatal depression and consider recommended pharmaceutical and psychosocial management of postpartum blues, perinatal depression and postpartum psychosis.
\end{abstract}

\section{LEARNING OBJECTIVES}

- Delineate the aetiological and epidemiological factors associated with the development of perinatal depression

- Appreciate the differential diagnosis and assessment of risk in perinatal depression and postnatal psychosis

- Highlight main pharmacological and psychosocial recommendations for the management of perinatal depression and psychosis

\section{DECLARATION OF INTEREST}

None

More than 150 years ago, the French psychiatrist Louis Victor Marcé wrote Traité de la folie des femmes enceintes, des nouvelles accouchées et des nourrices (Treatise on the psychoses of pregnant women, and newly delivered and nursing mothers) (Marcé 1858). Marcé is today considered the founding father of 'perinatal psychiatry' and the first to describe postpartum psychosis. A quarter of a century ago, Kendell and colleagues demonstrated that women experience a dramatic increase in their risk of developing severe mental illness in the first 3 months after delivery (Kendell 1987). Subsequent studies have corroborated this. During the postpartum period, about $85 \%$ of women experience some type of mood disturbance (Henshaw 2003). For most women the symptoms are mild and short-lived, resolving generally within a week. However, 10-15\% of women have clinically significant symptoms of depression or anxiety (Cox 1993). Perinatal mood-related events have typically been divided into three categories: postpartum blues, perinatal depression and postpartum psychosis (Table 1). We will discuss each of these individually later in this article, but first we will consider general diagnostic and aetiological factors relating primarily to perinatal mood disorders.

\section{Diagnostic classification}

Although perinatal depression was initially conceptualised as a disorder specifically related to childbirth and clinically different from other types of depression, more recent evidence suggests that depression occurring during the perinatal period might be clinically indistinguishable from depression at other times in women's lives (O'Hara 1990; Evans 2001; Cooper 2007).

Perinatal mental illnesses are not listed separately in DSM-5 (American Psychiatric Association 2013) or in ICD-10 (World Health Organization 2010), but psychiatrists all over the world have retained the terms 'perinatal depression' and 'postpartum psychosis' to refer to episodes occurring during pregnancy and/or after delivery. The main advantage of such a distinction is that it carries prognostic information concerning risk in future pregnancies. In women with a diagnosis of bipolar illness, those who experience a puerperal

\section{TABLE 1}

Classification and incidence of perinatal/postpartum psychiatric events

\begin{tabular}{|lcll|}
\hline & Incidence $^{\text {a }}$ & Onset & Symptoms (DSM-5) $^{\mathbf{b}}$ \\
\hline $\begin{array}{l}\text { Postpartum blues } \\
\text { (maternity blues) }\end{array}$ & $50-85 \%$ & $\begin{array}{l}\text { Within 1 week } \\
\text { postpartum }\end{array}$ & $\begin{array}{l}\text { Fluctuating, labile mood; } \\
\text { anxiety; tearfulness }\end{array}$ \\
\hline Perinatal depression & $10-15 \%$ & $\begin{array}{l}\text { Insidious, during } \\
\text { pregnancy or within } \\
\text { first 3 months } \\
\text { postpartum }\end{array}$ & $\begin{array}{l}\text { Depressed mood; prominent } \\
\text { anxiety symptoms }\end{array}$ \\
\hline $\begin{array}{l}\text { Postpartum psychosis } \\
\text { (affective puerperal } \\
\text { psychosis) }\end{array}$ & $0.1-0.2 \%$ & $\begin{array}{l}\text { Dramatic, within 2 } \\
\text { weeks postpartum }\end{array}$ & $\begin{array}{l}\text { Mania and/or mixed affective } \\
\text { state: agitation, mixed mood, } \\
\text { bewilderment, delusions, } \\
\text { disorganised behaviour }\end{array}$ \\
\hline
\end{tabular}

a. From Sit et al (2006).

b. From American Psychiatric Association (2013)
Myles Doyle is a consultant psychiatrist in North Tipperary and Research Fellow at the Institute of Neuroscience, Trinity College Dublin, Ireland. Angela Carballedo is a consultant psychiatrist at Cluain Mhuire, St John of God Hospital, Dublin, and a senior clinical lecturer at the Institute of Neuroscience, Trinity College Dublin. Veronica O'Keane is Professor of Psychiatry at Trinity College Institute of Neuroscience and the Adelaide and Meath Hospital, Dublin.

Correspondence Dr Angela Carballedo, Institute of Neuroscience, College Green, Trinity College Dublin, Dublin D2, Ireland. Email: carbala@tcd.ie 
(postpartum) psychosis have more than a 60\% risk of recurrence of psychosis following a further pregnancy, compared with a risk of $25 \%$ for those who do not experience a postpartum episode (Robertson 2005). An episode of perinatal depression increases the risk of further perinatal depressive episodes with future pregnancies. Furthermore, an episode of depression in the perinatal period confers a higher risk of recurring perinatal depression than does a history of nonperinatal depression (Johnstone 2001; Josefsson 2002; Forty 2006).

\section{Aetiology of perinatal and postnatal depressive illness}

The aetiology of postpartum (maternity) blues is still unknown. However, women with maternity blues are more likely to have a history of premenstrual tension and neuroticism, and to have experienced anxiety and depressed mood during pregnancy (Kennerley 1989).

\section{Hormonal changes and the HPA axis}

It is likely that the massive hormonal reequilibration process following delivery results in brain changes that lead to the temporary experience of unstable mood (Harris 1994, 1996). Progesterone is the main gestational steroid and it has been studied in relation to the onset of perinatal depression. There is no difference in either progesterone levels or the rates of decline of this and other hormones post-delivery between women who develop postnatal depression and women who do not (Harris 1994, 1996). Harris et al did, however, find a difference between cortisol levels during the puerperium and at the onset of depression.

A woman's hypothalamic-pituitary-adrenal (HPA) axis undergoes gradual changes during pregnancy because of an increasing production of placental corticotrophin-releasing hormone (CRH). The abrupt withdrawal of placental CRH at birth results in a re-equilibration of the HPA axis in the days post-delivery. These changes may be involved in the aetiology of postpartum blues, given the central role of the HPA axis in the aetiology of mood disorders in general, and in perinatal depression in particular (O'Keane 2011a).

Depression during pregnancy has also been associated with increased activity of the HPA axis and diminished length of gestation (O'Keane 2008), and may have implications for development of the fetal HPA axis. A pilot study in which one of us was involved (O'Keane 2011b) made a prospective comparison of HPA axis variables in depressed and non-depressed pregnant women. The study showed for the first time that the depressed women had higher levels of secondtrimester $\mathrm{CRH}$ and free evening cortisol than the non-depressed women, results that mirror HPA axis findings in depression outside of pregnancy. Some investigators hypothesise that a subgroup of women are particularly sensitive to the HPA changes that take place during pregnancy and after delivery. These women may be more vulnerable to perinatal depression and to other hormonally driven mood disturbances, such as those occurring during the premenstrual phase of the menstrual cycle or during the perimenopause (Bloch 2000).

\section{Obstetric factors}

Various obstetric factors have been considered in relation to perinatal depression. These include pregnancy-related complications (such as preeclampsia, hyperemesis, premature contractions) and delivery-related complications (such as emergency/elective Caesarean, instrumental delivery, premature delivery and excessive bleeding intrapartum). Recent studies, however, have found no overall statistically significant relationship between such factors and perinatal depression (Warner 1996; Forman 2000).

\section{Family history of psychiatric illness}

A meta-analysis of six studies (involving about 900 women) revealed that there was no association between family history of depression and perinatal depression (O’Hara 1996). However, Johnstone et al (2001) did find an increased risk of perinatal depression in a study of 490 women with a family history of mental illness, personal history of depression or anxiety or a history of depression in the participant's mother; and Forty et al (2006) found that episodes of depression with onset within 4 weeks of delivery clustered in families.

\section{Depression during or before pregnancy}

It has also been found that depressed mood during pregnancy predicts the presence of depression in the postnatal period and that around 50\% of episodes of postnatal depression start during pregnancy (Neter 1995; Johnstone 2001; Josefsson 2002). A personal history of recurrent major depression is a very strong risk factor for the occurrence of perinatal depression: around $40 \%$ of pregnancies result in relapse (Di Florio 2013).

\section{Other psychological and social risk factors}

Other psychological and social risk factors may play a role in the aetiology of perinatal depression. A negative cognitive attributional style, as would be expected, has been more strongly related 
to high levels of depressive symptomatology assessed through self-report (O'Hara 1996). Life events have also been associated with onset of depression (Brown 1978). A meta-analysis found a moderate relationship between perceived life stress and perinatal depression (Beck 2001). This moderate risk has been repeatedly demonstrated to be mediated by poor partner support and/ or inadequate social and/or economic supports (Dayan 2010). Stressful life events occurring either during pregnancy or near the time of delivery may increase the likelihood of perinatal depression (Beck 2001). A study conducted by Lee and colleagues showed an association between temporary accommodation, financial difficulties, two or more induced abortions and postnatal depression (Lee 2000). Two studies have highlighted the importance of perceived social isolation (or lack of social support), finding this to be a strong risk factor for antenatal depressive symptoms (Seguin 1999; Forman 2000). An important recognised risk factor for the development of both ante- and postnatal depression is severe childhood adversity (Dayan 2010).

\section{Postpartum blues}

It appears that about 50-85\% of women experience postpartum blues during the first week after delivery (Henshaw 2003). Given how common and self-limiting this type of mood disturbance is, it may be more accurate to consider the blues as a normal experience following childbirth rather than as a psychiatric disorder.

This interesting syndrome was reviewed in great detail by Stein (1982). Rather than feelings of sadness, women with what Stein calls the maternity blues more commonly report mood lability (mood can be also elevated temporarily), tearfulness, anxiety or irritability. Crying spells are the hallmark of the maternity blues. These symptoms typically peak on the fourth or fifth day after delivery and may last for a few hours or a few days, remitting spontaneously within 2 weeks after delivery. Although the occurrence of these experiences is sudden, unpredictable and often unsettling, they generally do not interfere with a woman's ability to function.

Heron et al (2005) reviewed the literature on milder forms of elation occurring in the puerperium. Although these symptoms may often be regarded as clinically insignificant, and part of the maternity blues, there is evidence that the experience of minor puerperal elation may be a predictor of later postpartum depression.

No specific treatment is required for postpartum blues, apart from support and reassurance, owing to the self-limiting nature of the episode (NICE 2007; Royal College of Obstetricians and Gynaecologists 2011; Scottish Intercollegiate Guidelines Network (SIGN) 2012). However, it should be noted that sometimes the blues herald the development of a more significant mood disorder, particularly in women who have a history of depression (Sutter 1997). Studies from various countries demonstrate that severe blues increase the risk of postpartum depression (e.g. Henshaw 2004; Adewuya 2006; Watanabe 2008; Reck 2009).

\section{Perinatal depression}

\section{Effects on the mother and child}

The effects of depression on the mother, her marital relationship and her children make it an important condition to diagnose, treat and prevent (Robinson 2001). Guidelines on the clinical management of antenatal and postnatal mental health (e.g. NICE 2007; Royal College of Obstetricians and Gynaecologists 2011; SIGN 2012) highlight the importance of detection during pregnancy and the postnatal period, as untreated depression can have long-lasting adverse effects.

For the mother, the episode can be the precursor of chronic recurrent depression (Campbell 1997; Pawlby 2009), and suicide resulting from puerperal mental illness is one of the leading causes of death among women during the perinatal period (Confidential Enquiry into Maternal and Child Health 2004, 2007, 2011).

A mother's ongoing depression can contribute to emotional, behavioural (Hay 2001, 2003), cognitive and interpersonal problems in the later life of the child (Jacobsen 1999). Pawlby and colleagues followed up women with histories of depression during pregnancy/postpartum and their children at 11 and 16 years. They concluded that the children of mothers who met ICD-10 criteria for perinatal depression at 3 months postpartum were four times more likely than those whose mothers had been well in the postnatal period to suffer from a psychiatric disorder themselves at 11 years of age (Pawlby 2008). In a different sample (Pawlby 2009), they found that two-thirds of the women who first suffered antenatal depression during pregnancy experienced further episodes of depression later in life. In addition, $14 \%$ of the offspring of the women with antenatal depression were diagnosed with depression at age 16 . Most interestingly, every depressed adolescent had been exposed to maternal depression. There was a 4.7-fold greater odds of depression among the 16-year-olds who had been exposed to maternal antenatal depression than among those who were not exposed. 


\section{Prevalence of perinatal depression}

Perinatal depression is the most common complication of childbearing, affecting about 10$15 \%$ of women. Some studies did not find depression to be more common in the perinatal period than at any other stage in life (Cooper 1988; O'Hara 1990; Cox 1993). However, more recent studies have demonstrated an increased risk of postnatal depression. Using the Danish psychiatric admission and birth registries, Munk-Olsen and colleagues, for example, found a threefold increased risk of admission with unipolar depression on postpartum days 31-60 (Munk-Olsen 2006). The relative risk (RR) for admission with unipolar depression in pregnancy was 0.44 (95\% CI 0.31-0.62) compared with 3.53 (95\% CI 2.47-5.05) in the postpartum period. For bipolar illness, the increased risk was even more dramatic, with an RR of 0.19 (95\% CI 0.04-0.86) for admission during pregnancy and of 23.33 (95\% CI 11.5-47.42) for admission during the first month postpartum.

\section{Onset and signs of perinatal depression}

Perinatal depression typically begins within 1-3 months of delivery. Some women actually note the onset of milder depressive symptoms during pregnancy, and for others, postpartum blues simply continue and become more severe. In others, a period of well-being after delivery is followed by a gradual onset of depression. However, what is clear is that a large percentage of women who are depressed during pregnancy remain depressed after birth (Leigh 2008), resulting in an increased risk of insecure attachment and impaired development of the child (Champagne 2006).

Perinatal depression may be clinically indistinguishable from depression occurring at other times during a woman's life (Wisner 2002), but the content of thinking may focus on the delivery or the baby. Some women worry excessively about the baby's health or feeding habits and see themselves as 'bad', inadequate or unloving mothers (Robinson 2001). Significant anxiety symptoms may also occur. Generalised anxiety is common, but some women also develop panic attacks or hypochondriasis. Postpartum obsessivecompulsive disorder has also been reported, where women have disturbing and intrusive thoughts of harming their infant.

It can be difficult to detect perinatal depression (Box 1), especially in milder cases, because many of the symptoms used to diagnose depression (e.g. sleep and appetite disturbance, fatigue) also occur in postpartum women in the absence of depression. Face-to-face clinical assessment and screening of women who are at risk of perinatal depression is paramount. The Edinburgh Postnatal Depression Scale (EPDS; Cox 1987) is a 10-item questionnaire that may be used to identify/screen women who have perinatal depression. On this scale, a score of 12 or greater, or an affirmative answer on question 10 (presence of suicidal thoughts), raise concern and indicate a need for more thorough evaluation. The current recommendation is that for a score $>11$ a re-evaluation should take place within 2 weeks, unless there are concerns about suicidal ideation or significant deterioration in mental state, which should prompt to immediate referral to a psychiatrist (Gibson 2009; Hewitt 2009).

\section{Postpartum psychosis}

Hippocrates first described puerperal psychosis in the 5th century Bc, thinking that it was the result of breast milk accidentally entering the brain. Postpartum psychosis is the most severe form of perinatal psychiatric illness. It is a rare event that occurs in approximately 1-2 women per 1000 after childbirth (Kendell 1987). Its presentation is often dramatic, with onset of symptoms sometimes before delivery, and frequently in the first 48-72 hours after delivery. Around $50 \%$ of women who experience postpartum psychosis start to develop symptoms on days $1-3$, with $22 \%$ of those showing symptoms as early as day 1 (Heron 2007). Kendell demonstrated that, in the 3 months following childbirth, women are more than 20 times more likely to be admitted to hospital with a diagnosis of a psychotic disorder than at any other time in their lives (Kendell 1976). Terp \& Mortensen found that the relative risk of first admission with functional psychosis between days 2 and 28 was 3.21 (Terp 1998). More recently, Harlow and colleagues noted that hospital admission was mainly confined to women who had previously had a history of psychosis or bipolar illness, and that most of the postpartum episodes occurred within

BOX 1 Symptoms of perinatal depression

- Depressed or low mood

- Tearfulness

- Loss of interest in usual activities

- Feelings of guilt

- Feelings of worthlessness or incompetence as a mother

- Fatigue

- Sleep disturbance

- Change in appetite

- Poor concentration

- Suicidal thoughts 
4 weeks of delivery (Harlow 2007). Munk-Olsen's group also found that the risk of admission was increased in the first 3 months and was highest for first-time mothers 10-19 days postpartum (MunkOlsen 2006). Another study has shown that women with bipolar I disorder reported an approximately $50 \%$ risk of a perinatal major affective episode per pregnancy/postpartum period (Di Florio 2013). It also found that most perinatal episodes occurred in the first month postpartum, with mania and psychosis having an earlier onset than depression.

\section{Signs of postpartum psychosis}

Earliest signs of postpartum psychosis include restlessness, feeling energetic or active, irritability, over-talkativeness and insomnia (Heron 2007) (Box 2). Women with the disorder exhibit a rapid shift between depressed and elated mood, disorientation or confusion, and erratic or disorganised behaviour (Heron 2008). Delusional beliefs are common and often centre on the infant. Auditory hallucinations that instruct the mother to harm herself or her infant may also occur. The risk of infanticide in postpartum psychosis is low (Appleby 1996; Altshuler 1998; Schalekamp 2005), as it is for suicide (Oates 2003). However, the latest report of the confidential enquiries into maternal deaths in the UK states: 'The last three Enquiry Reports found that maternal suicide was more common than previously thought and was a leading overall cause of maternal death', hence the need to screen and identify high-risk cases (Oates 2011: p. 133).

This type of psychotic presentation in the puerperium has reminded many authors of the 'cycloid psychosis' and 'boufée delirante' described by Leonhard (1961), Perris (1974) and others (Kleist 1929; Pfuhlmann 1998). In the words of Orlikov (2011), this is an illness of 'acute onset, cyclic course with full recovery in between, intense involvement of anxiety, psychomotor agitation, affective dysregulation, polymorphous delusions, and hallucinations'. These authors highlighted the favourable prognosis of the illness, the sudden or acute onset and the shifting nature of the symptoms, with opposite polar phases in the same

\section{B0X 2 Early symptoms of postpartum psychosis}

- Restlessness, agitation or perplexity

- Feeling energetic or active

- Overtalkativeness

- Irritability

- Insomnia episode (mood swings, confusion, hyperactivity, perplexity, deep feelings of happiness or ecstasy, and particular concern with death or dying).

\section{Prognosis of postpartum psychosis}

The prognosis of an acute episode is generally good, with most women making a good recovery and returning to premorbid levels of functioning. However, the risk of further episodes of psychosis both after subsequent pregnancies and at other times is high as mentioned earlier. Garfield et al followed up 66 women during 10 years after hospital admission for puerperal illness. The recurrence rate was $87.2 \%$ and the readmission rate was $63.3 \%$, with psychiatric history being the strongest predictor of recurrence (Garfield 2004). Another very recent study has shown that the risk of readmission for non-puerperal psychosis, although gradually decreasing with time, remains high for many years after postpartum psychosis. Interestingly, their sample was followed-up for 30 years in total (Nager 2013).

\section{Preventive measures}

The Scottish Intercollegiate Guidelines Network (2012) recommends that all pregnant women be asked about personal history of postpartum psychosis, other psychotic disorders (especially bipolar affective disorder and schizophrenia) and severe depressive disorder. All pregnant women should be asked about family history of bipolar disorder and postpartum psychosis.

Women at high risk of perinatal mental illness should have a detailed plan for their late pregnancy and early postnatal psychiatric management, agreed with the woman and shared with maternity services, the community midwifery team, general practitioner (GP), health visitor, mental health services and the woman herself. With the woman's agreement, a copy of the plan should be kept in the hand-held records that she takes to antenatal appointments. The plan should identify what support should be in place and who to contact if problems arise, together with their contact details (including out of hours). It should also address decisions on medication management in late pregnancy, the immediate postnatal period and if breastfeeding. Enquiry about depressive symptoms should be made, at minimum, on booking in and postnatally at 4-6 weeks and 3-4 months.

All women of childbearing potential who take psychotropic medication should be made aware of the possible effects of medications in pregnancy. The use of reliable contraceptive methods should be discussed. In view of the risk of early teratogenicity and longer-term neurobehavioural 
toxicity, valproate (as a mood stabiliser) should not be routinely prescribed to women of childbearing potential.

\section{Assessment of postpartum affective disorder}

Postpartum depression and psychosis present as a continuum, and the type of treatment selected is based on the severity and type of symptoms. However, before initiating psychiatric treatment, medical causes for mood disturbance (e.g. thyroid dysfunction, anaemia) must be excluded. Initial evaluation should include a thorough history, physical examination and routine laboratory tests. It is paramount to assess suicidality and infanticidal ideas. Delusions should be clearly defined and their content explored. One study found that $53 \%$ of women with severe postpartum mental illness and $78 \%$ of those with psychotic postpartum disorders had delusional beliefs about their infant (Chandra 2006). Close observation of mother and baby interaction is very important to elucidate psychopathology. Rating scales can assist the clinician in exploring abnormalities in the mother-infant relationship and bonding (Box 3).

In our increasingly multicultural Western society it is important to consider the cultural and ethnic background when assessing the level of support of pregnant and new mothers. Rituals practised within some cultures may be protective against postnatal mental illness because they provide social and practical support for the new mother. However, mental health problems are heavily stigmatised within many cultures, and women and their families may be reluctant to seek help from health professionals, preferring to try to manage the illness with no outside help. Health professionals may be consulted only when the woman is so severely ill that the family can no longer cope (Oates 2004).

\section{Psychological interventions for perinatal affective disorder}

Guidelines from NICE (2007) and SIGN (2012) recommend that, in non-emergencies, before pharmacological treatment decisions are made, healthcare professionals discuss with the woman the absolute and relative risks associated with treating and not treating the mental disorder during pregnancy and the postnatal period. They should:

- acknowledge the uncertainty regarding the risks

- explain the background risk of fetal malformations in pregnant women without a mental disorder

- describe risks using natural frequencies rather than percentages (e.g. 1 in 10, rather than 10\%)
BOX 3 Some rating scales assessing motherinfant relationship

Mother-infant interaction:

- The Bethlem Mother-Infant Interaction Scale (Kumar 1996)

Mother-infant attachment:

- Screening questionnaire for mother-infant bonding disorders (Brockington 2001)

- Mother-to-Infant Bonding Scale (Taylor 2005)

and common denominators (for example, 1 in 100 and 25 in 100)

- if possible, use decision aids in a variety of verbal and visual formats that focus on an individualised view of the risks, and provide written material (preferably individualised) to explain these risks; if possible, audio records of the consultation should be kept.

SIGN suggests that cognitive-behavioural therapies (CBTs) should be considered for treatment of mild to moderate depression in the postnatal period. For a woman who develops mild or moderate depression during pregnancy or the postnatal period, NICE advises the following:

- self-help strategies: guided self-help, computerised CBT or exercise

- non-directive counselling delivered at home (listening visits)

- brief CBT or interpersonal psychotherapy.

A randomised study found short-term CBT to be as effective as treatment with fluoxetine in women with perinatal depression (Appleby 1997). CBT has also been shown to be effective in preventing further episodes of perinatal depression (Nardi 2012). Interpersonal psychotherapy is effective not only for mild to moderate depression, but women who receive interpersonal psychotherapy also benefit from significant improvement in the quality of their interpersonal relationships (Reay 2012; Stuart 2012). These non-pharmacological interventions may be particularly attractive to patients who are reluctant to use psychotropic medications (e.g. women who are breastfeeding) or for patients with milder forms of depressive illness.

\section{Pharmacological treatment for perinatal affective disorder}

Clinicians should be cautious about prescribing during pregnancy and breastfeeding, owing to the possible risks to the fetus and infant. The principles set out in Box 4 should apply. 
BOX 4 Principles for prescribing pharmacotherapy in pregnancy and during breastfeeding

- Establish a clear indication for the pharmacological treatment, involving the woman and her family in the discussion

- Choose treatments with the lowest known risk

- Use medication at the lowest effective dose and for the shortest period of time

- Be aware of potential drug interactions and aim at monotherapy

- Be aware of the potential effects of pregnancy and childbirth on drug pharmacokinetics and pharmacodynamics

- Where the risk is known, ensure that fetal screening and monitoring of the neonate are offered

- Monitor for specific side-effects as well as feeding patterns, growth and development

- Caution women against sleeping in bed with the baby if they are taking sedative drugs

(Sign 2012)

\section{During pregnancy}

For a woman with serious mental illness, at high risk of relapse, discontinuation of treatment may be unwise: relapse may ultimately be more harmful to the mother and child than continuing drug treatment. Nevertheless, clinicians should be aware that antidepressants have been associated with spontaneous abortions, congenital malformations, poor neonatal adaptation, persistent pulmonary hypertension in the newborn and other neurodevelopmental outcomes in the child (Hemels 2005; Lattimore 2005; Rahimi 2006; Udechuku 2010). However, another study (Warburton 2010) has shown that, controlling for severity of maternal illness, reducing exposure to selective serotonin reuptake inhibitors (SSRIs) at the end of pregnancy had no significant clinical effect on improving neonatal health. These findings have given rise to the possibility that some adverse neonatal outcomes may not be an acute pharmacological condition such as toxicity or withdrawal. SIGN (2012) recommends that paroxetine should not be used as first-line therapy in pregnancy (see also UK Teratology Information Service 2011).

Lithium and anti-epileptic drugs have been associated with congenital malformations, neurological effects on the neonate and other complications (Newport 2005; UK Teratology Information Service 2009; Galbally 2010; Cunnington 2011). Valproate should not be prescribed in pregnancy (SIGN 2005; Nicolai
2008). Women taking antipsychotics during pregnancy should be monitored for alterations in fetal growth and maternal blood glucose levels should be monitored when taking olanzapine or clozapine (Gentile 2010; McCauley-Elsom 2010).

\section{In the postnatal period}

\section{Depression}

Women with more severe postpartum depression may choose to receive pharmacological treatment, either in addition to or instead of non-pharmacological therapies. SSRIs and tricyclic antidepressants (TCAs) may be offered for the treatment of moderate to severe postnatal depression with considerations when breastfeeding (SIGN 2012). To date, only a few studies have systematically assessed the pharmacological treatment of postnatal depression. Conventional antidepressant medications have shown efficacy (Molyneaux 2014) and standard doses seem effective and well tolerated. The choice of an antidepressant should be guided by the patient's response to previous antidepressant medication and the medication's side-effect profile. SSRIs are ideal first-line agents, as they are anxiolytic, nonsedating and well tolerated. For women who cannot tolerate SSRIs, bupropion may be an alternative. TCAs are frequently used and, because they tend to be more sedating, may be more appropriate for women who present with prominent sleep disturbance. Given the prevalence of anxiety symptoms in this population, adjunctive use of a benzodiazepine (e.g. clonazepam, lorazepam) may be very helpful.

\section{Postpartum psychosis}

Most women with acute psychotic episodes postpartum need to be admitted to hospital, as do those with severe depression or at risk to self or others. Ideally, they should be admitted, with their babies, to specialist perinatal or mother and baby units, where they can recover from the psychotic episode and bond to their infant.

Medication for an acute psychotic episode is not different to that given outside the perinatal period, but the prolactin-elevating properties of potent dopamine-2 receptor blocking drugs should be a consideration for women who have decided not to breastfeed or who are too ill to manage it. Given the well-established relationship between puerperal psychosis and bipolar disorder, postpartum psychosis should be treated as an affective psychosis and a mood stabiliser is indicated. Interestingly, a recent study has recommended initiating prophylaxis with lithium therapy in women with a history of psychosis 
limited to the postpartum period (Bergink 2012). Electroconvulsive therapy (ECT) is well tolerated and rapidly effective for severe postpartum depression and psychosis (Focht 2012).

\section{Psychotropic medication and breastfeeding}

Clinicians should support women in their choice to breastfeed after clear discussions of the benefits and risks when on psychotropic medication (SIGN 2012). When initiating treatment, consideration should be given to the absolute dose and half-life of the drug. The following should be noted for specific drugs.

- Doxepine should be avoided if considering breastfeeding (SIGN 2012) and if an SSRI is needed. The Maudsley guidelines recommend paroxetine or sertraline (Taylor 2009).

- Mothers on lithium should be encouraged not to breastfeed, but if they decide to do it, close monitoring of the infant is necessary, including serum lithium, thyroid and renal functioning.

- Anti-epileptic drugs are not a contraindication for breastfeeding, but benefits and risks should be discussed with the mother in detail.

- If a benzodiazepine is required, then short-acting agents should be prescribed and in divided doses. Mothers should be advised not to stop the medication abruptly (because of the risk of discontinuation syndrome) and to seek medical advice if they note sleepiness or poor sucking in their babies. All breastfed infants should be monitored for sedation and extrapyramidal side-effects where mothers are taking antipsychotic medications.

- Women on clozapine should not breastfeed because of the risk of agranulocytosis.

\section{Conclusions}

Mild and short-lived mood disturbance during pregnancy and postpartum is common, but a minority of women develop depressive illness or sudden psychosis. It is important to be vigilant for symptoms of mental illness during both pregnancy and the postpartum period: about half of episodes of so-called postnatal depression start during pregnancy, and some seemingly postpartum psychotic episodes start before delivery. It is essential to keep in mind that untreated antenatal depression can lead to poor outcomes not only for the mother but also for the child.

\section{References}

Adewuya A0 (2006) Early postpartum mood as a risk factor for postnatal depression in Nigerian women. American Journal of Psychiatry, 163: $1435-7$.

Altshuler LL, Hendrick V, Cohen LS (1998) Course of mood and anxiety disorders during pregnancy and the postpartum period. Journal of Clinical Psychiatry, 59: 29-33.
American Psychiatric Association (2013) Diagnostic and Statistical Manual of Mental Disorders (5th edn) (DSM-5). APA.

Appleby L (1996) Suicidal behavior in childbearing women. International Review of Psychiatry, 8: 107-15.

Appleby L, Warner R, Whitton A (1997) A controlled study of fluoxetine and cognitive-behavioural counselling in the treatment of postnatal depression. BMJ, 14: 932-6.

Beck CT (2001) Predictors of postpartum depression: an update. Nursing Research, 50: 275-85.

Bergink V, Bouvy PF, Vervoort JSP, et al (2012) Prevention of postpartum psychosis and mania in women at high risk. American Journal of Psychiatry, 169: 609-15.

Bloch M, Schmidt PJ, Danaceau M, et al (2000) Effects of gonadal steroids in women with a history of postpartum depression. American Journal of Psychiatry, 157: 924-30.

Brockington IF, Oates J, George S, et al (2001) A Screening Questionnaire for mother-infant bonding disorders. Archives of Women's Mental Health, 3: $133-40$

Brown GW, Harris T (1978) Social Origins of Depression: A Study of Psychiatric Disorder in Women. Free Press.

Campbell SB, Cohn JF (1997) The timing and chronicity of postpartum depression: implications for infant development. In Postpartum Depression and Child Development (eds L Murray, P Cooper): 165-97. Guilford.

Champagne FA, Meaney MJ (2006) Stress during gestation alters postpartum maternal care and the development of the offspring in a rodent model. Biological Psychiatry, 59: 1227-35.

Chandra PS, Bhargavarman RP, Raghunandan VNGP, et al (2006) Delusions related to infants and their association with mother-infant interactions in postpartum psychotic disorders. Archives of Women's Health, 9: 285-8.

Confidential Enquiry into Maternal and Child Health (2004) Why Mothers Die 2000-2002. The Sixth Report of the Confidential Enquiries into Maternal Deaths in the United Kingdom. RCOG Press.

Confidential Enquiry into Maternal and Child Health (2007) Saving Mothers' Lives: Reviewing Maternal Deaths to Make Motherhood Safer 2003-2005. The Seventh Report of the Confidential Enquiries into Maternal Deaths in the United Kingdom. CEMACH.

Confidential Enquiry into Maternal and Child Health (2011) Saving Mothers' Lives: Reviewing Maternal Deaths to Make Motherhood Safer 2006-2008. The Eighth Report of the Confidential Enquiries into Maternal Deaths in the United Kingdom. BJOG, 118 (suppl 1): 1-203.

Cooper PJ, Campbell EA, Day A, et al (1988) Non-psychotic psychiatric disorder after childbirth: a prospective study of prevalence, incidence, course and nature. British Journal of Psychiatry, 152: 799-806.

Cooper C, Jones L, Dunn E, et al (2007) Clinical presentation of postnatal and non-postnatal depressive episodes. Psychological Medicine, 37 . 1273-80.

Cox JL, Holden JM, Sagovsky R (1987) Detection of postnatal depression: development of the 10-item Edinburgh Postnatal Depression Scale. British Journal of Psychiatry, 150: 782-6.

Cox JL, Murray D, Chapman G (1993) A controlled study of the onset, duration and prevalence of postnatal depression. British Journal of Psychiatry, 163: 27-31

Cunnington MC, Weil JG, Messenheimer JA, et al (2011) Final results from 18 years of the International Lamotrigine Pregnancy Registry. Neurology, 76: 1817-23

Dayan J, Creveuil C, Dreyfus M, et al (2010) Developmental model of depression applied to prenatal depression: role of present and past life events, past emotional disorders and pregnancy stress. PLoS One, 5: e12942.

Di Florio A, Forty L, Gordon-Smith K, et al (2013) Perinatal episodes across the mood disorder spectrum. JAMA Psychiatry, 70: 168-75.

Evans J, Heron J, Francomb H, et al (2001) Cohort study of depressed mood during pregnancy and after childbirth. BMJ, 323: 257-60.

Focht A, Kellner $\mathrm{CH}$ (2012) Electroconvulsive therapy (ECT) in the treatment of postpartum psychosis. Journal of ECT, 1: 31-3. 
Forman DN, Videbech P, Hedegaard M, et al (2000) Postpartum depression: identification of women at risk. British Journal of Obstetrics and Gynaecology, 107: 1210-7.

Forty L, Jones L, Macgregor S, et al (2006) Familiality of postpartum depression in unipolar disorder: results of a family study. American Journal of Psychiatry, 163: 1549-53.

Galbally M, Roberts M, Buist A (2010) Mood stabilizers in pregnancy: a systematic review. Australian and New Zealand Journal of Psychiatry, 44: 967-77.

Garfield P, Kent A, Paykel ES, et al (2004) Outcome of postpartum disorders: a 10 year follow-up of hospital admissions. Acta Psychiatrica Scandinavica, 109: 434-9.

Gentile S (2010) Antipsychotic therapy during early and late pregnancy: a systematic review. Schizophrenia Bulletin, 36: 518-44.

Gibson J, McKenzie-McHarg K, Shakespeare J, et al (2009) A systematic review of studies validating the Edinburgh Postnatal Depression Scale in antepartum and postpartum women. Acta Psychiatrica Scandinavica, 119: 350-64

Harlow BL, Vitonis AF, Sparen P, et al (2007) Incidence of hospitalization for postpartum psychotic and bipolar episodes in women with and without prior prepregnancy or prenatal psychiatric hospitalizations. Archives of General Psychiatry, 64: 42-8.

Harris B, Lovett L, Newcombe RG, et al (1994) Maternity blues and major endocrine changes: Cardiff puerperal mood and hormone study. II. BMJ, 308: 949-53.

Harris B, Lovett L, Smith J, et al (1996) Cardiff puerperal mood and hormone study. III. Postnatal depression at 5 to 6 weeks postpartum, and its hormonal correlates across the peripartum period. British Journal of Psychiatry, 168: 739-44.

Hay DF, Pawlby S, Sharp D, et al (2001) Intellectual problems shown by 11-year-old children whose mothers had postnatal depression. Journal of Child Psychology and Psychiatry, 42: 871-90.

Hay DF, Pawlby S, Angold A, et al (2003) Pathways to violence in the children of mothers who were depressed postpartum. Developmental Psychology, 39: 1083-94.

Hemels MEH, Einarson A, Koren G, et al (2005) Antidepressant use during pregnancy and the rates of spontaneous abortions: a meta-analysis. Annals of Pharmacotherapy, 39: 803-9.

Henshaw C (2003) Mood disturbance in the early puerperium: a review. Archives of Women's Mental Health, 6 (suppl 2): S33-42.

Henshaw C, Foreman D, Cox J (2004) Postnatal blues: a risk factor for postnatal depression. Journal of Psychosomatic Obstetrics and Gynaecology, 25: 267-72.

Heron J, Craddock N, Jones I (2005) Postnatal euphoria: are 'the highs' an indicator of bipolarity? Bipolar Disorders, 7: 103-10.

Heron J, Robertson Blackmore E, McGuinness M, et al (2007) No 'latent period' in the onset of bipolar affective puerperal psychosis. Archives of Women's Mental Health, 10: 79-81.

Heron J, McGuinness M, Robertson Blackmore E, et al (2008) Early postpartum symptoms in puerperal psychosis. BJOG, 115: 348-53.

Hewitt C, Gilbody S, Brealey S, et al (2009) Methods to identify postnatal depression in primary care: an integrated evidence synthesis and value of information analysis. Health Technology Assessment, 13 (36): 1-230.

Jacobsen T (1999) Effects of postpartum disorders on parenting and on offspring. In Postpartum Mood Disorders (ed LJ Miller): 119-39. American Psychiatric Press.

Johnstone SJ, Boyce PM, Hickey AR, et al (2001) Obstetric risk factors for postnatal depression in urban and rural community samples. Australian and New Zealand Journal of Psychiatry, 35: 69-74.

Josefsson A, Angelsiöö L, Berg G, et al (2002) Obstetric, somatic, and demographic risk factors for postpartum depressive symptoms. Obstetrics and Gynecology, 99: 223-8.

Kendell RE, Wainwright S, Hailey A, et al (1976) The influence of childbirth on psychiatric morbidity. Psychological Medicine, 6: 297-302.

Kendell RE, Chalmers JC, Platz C (1987) Epidemiology of puerperal psychoses. British Journal of Psychiatry, 150: 662-73.
Kennerley H, Gath D (1989) Maternity blues. III. Associations with obstetric, psychological, and psychiatric factors. British Journal of Psychiatry, 155: 367-73.

Kleist K (1929) Uber cykloide, paranoide, und epileptoide Psychosen und uber die Frage der Degenerationspsychosen [On cycloid, paranoid and epileptoid psychoses and on the question of degenerative psychoses]. Schweizer Archiv für Neurologie und Psychiatrie, 23: 3-37.

Kumar R, Hipwell AE (1996) Development of a clinical rating scale to assess mother-infant interaction in a psychiatric mother and baby unit. British Journal of Psychiatry, 169: 18-26.

Lattimore KA, Donn SM, Kaciroti N, et al (2005) Selective serotonin reuptake inhibitor (SSRI) use during pregnancy and effects on the fetus and newborn: a meta-analysis. Journal of Perinatology, 25: 595-604.

Lee DT, Yip AS, Leung TY, et al (2000) Identifying women at risk of postnatal depression: prospective longitudinal study. Hong Kong Medical Journal, 6: 349-54.

Leigh B, Milgrom J (2008) Risk factors for antenatal depression, postnatal depression and parenting stress. BMC Psychiatry, 8: 24.

Leonhard K (1961) Cycloid psychoses: endogenous psychoses which are neither schizophrenic nor manic-depressive. Journal of Mental Science, 107: $632-48$

Marcé LV (1858) Traité de la folie des femmes enceintes, des nouvelles accouchées et des nourrices [Treatise on the psychoses of pregnant women, and newly delivered and nursing mothers]. J.B. Baillière et Fils.

McCauley-Elsom K, Gurvich C, Elsom SJ, et al (2010) Antipsychotics in pregnancy. Journal of Psychiatric and Mental Health Nursing, 17: 97-104.

Molyneaux E, Howard LM, McGeown HR, et al (2014) Antidepressant treatment for postnatal depression. Cochrane Database of Systematic Reviews, 9: CD002018

Munk-OIsen T, Laursen TM, Pedersen CB, et al (2006) New parents and mental disorders: a population-based register study. JAMA, 296: 2582-9.

Nager A, Szulkin R, Johansson SE, et al (2013) High lifelong relapse rate of psychiatric disorders among women with postpartum psychosis. Nordic Journal of Psychiatry, 67: 53-8.

Nardi B, Laurenzi S, di Nicolo M, et al (2012) Is the cognitive-behavioral therapy an effective intervention to prevent the postnatal depression? A critical review. International Journal of Psychiatry in Medicine, 43: $211-25$

National Institute for Health and Clinical Excellence (2007) Antenatal and Postnatal Mental Health: Clinical Management and Service Guidance (NICE Clinical Guideline CG45). NICE.

Neter E, Collins NL, Lobel M, et al (1995) Psychosocial predictors of postpartum depressed mood in socioeconomically disadvantaged women. Women's Health, 1: 51-75.

Newport DJ, Viguera AC, Beach AJ, et al (2005) Lithium placental passage and obstetrical outcome: Implications for clinical management during late pregnancy. American Journal of Psychiatry, 162: 2162-70.

Nicolai J, Vles JS, Aldenkamp AP (2008) Neurodevelopmental delay in children exposed to antiepileptic drugs in utero: A critical review directed at structural study-bias. Journal of the Neurological Sciences, 271: 1-14.

Oates M (2003) Perinatal psychiatric disorders: a leading cause of maternal morbidity and mortality. British Medical Bulletin, 67: 219-29.

Oates MR, Cox JL, Neema S, et al (2004) Postnatal depression across countries and cultures: a qualitative study. British Journal Psychiatry, 184 (suppl 46): s10-6.

Oates M, Cantwell R (2011) Deaths from psychiatric causes. British Journal of Obstetrics and Gynaecology, 118 (suppl 1): 132-42.

O'Hara MW, Zekovski EM, Philipps LH, et al (1990) Controlled prospective study of postpartum mood disorders: comparison of childbearing and nonchildbearing women. Journal of Abnormal Psychology, 99: 3-15.

O'Hara MW, Swain AM (1996) Rates and risk of postpartum depression: a meta-analysis. International Review of Psychiatry, 8: 37-54.

O'Keane V (2008) The endocrinology of maternofetal interactions and its influence on the later development of mood disorders. Journal of Affective Disorders, 107: s21-52.

\section{MCO answers}

$1 \mathrm{~b} \quad 2 \mathrm{~d} \quad 3 \mathrm{~b} \quad 4 \mathrm{a} \quad 5 \mathrm{c}$ 
O'Keane V, Lightman S, Marsh M, et al (2011a) Changes in the maternal hypothalamic-pituitary-adrenal axis during the early puerperium may be related to the postpartum 'Blues'. Journal of Neuroendocrinology, 23 . 1149-55.

O'Keane V, Lightman S, Marsh M, et al (2011b) Increased pituitary-adrenal activation and shortened gestation in a sample of depressed pregnant women: a pilot study. Journal of Affective Disorders, 130: 300-5.

Orlikov AB (2011) Two case reports of confusion psychosis: should we reevaluate the place of cycloid psychoses in modern psychiatry? Primary Care Companion for CNS Disorders, 13 (1): PCC.10101024.

Pawlby S, Sharp D, Hay D, et al (2008) Postnatal depression and child outcome at 11 years: the importance of accurate diagnosis. Journal of Affective Disorders, 107: 241-5.

Pawlby S, Hay DF, Sharp D, et al (2009) Antenatal depression predicts depression in adolescent offspring: prospective longitudinal communitybased study. Journal of Affective Disorders, 113: 236-43.

Perris C (1974) A study of cycloid psychoses. Acta Psychiatrica Scandinavica Supplementum, 253: 1-77.

Pfuhlmann B (1998) The concept of cycloid psychoses: developments, clinical significance and the state of research. Fortschritte der NeurologiePsychiatrie, 66: 1-9

Rahimi R, Nikfar S, Abdollahi M (2006) Pregnancy outcomes following exposure to serotonin reuptake inhibitors: a meta-analysis of clinical trials. Reproductive Toxicology, 22: $571-5$.

Reay RE, Owen C, Shadbolt B, et al (2012) Trajectories of long-term outcomes for postnatally depressed mothers treated with group interpersonal psychotherapy. Archives of Women's Mental Health, 15: 217-28.

Reck C, Stehle E, Reinig K, et al (2009) Maternity blues as a predictor of DSM-IV depression and anxiety disorders in the first three months postpartum. Journal of Affective Disorders, 113: 77-87.

Robertson E, Jones I, Haque $S$, et al (2005) Risk of puerperal and nonpuerperal recurrence of illness following bipolar affective puerperal (post-partum) psychosis. British Journal of Psychiatry, 186: 258-9.

Robinson GE, Stewart DE (2001) Postpartum disorders. In Psychological Aspects of Women's Health Care. The Interface between Psychiatry and Obstetrics and Gynecology (2nd edn) (eds NL Stotland, DE Stewart): 117-39. American Psychiatric Press

Royal College of Obstetricians and Gynaecologists (2011) Management of Women with Mental Health Issues during Pregnancy and the Postnatal Period Guideline (Good Practice No. 14). RCOG.

Schalekamp RJ (2005) Maternal Filicide-Suicide from a Suicide Perspective: Assessing Ideation (http://www.filicide-suicide.com). Accessed 14 Oct 2014

Scottish Intercollegiate Guidelines Network (2005) Diagnosis and Manage ment of Epilepsy in Adults: A National Clinical Guideline (SIGN 70). SIGN.

Scottish Intercollegiate Guidelines Network (2012) Management of Perinatal Mood Disorders: A National Clinical Guideline (SIGN 127). SIGN.
Seguin L, Potvin L, St Denis M, et al (1999) Depressive symptoms in the late postpartum among low socioeconomic status women. Birth, 26: $157-63$

Sit D, Rothschild AJ, Wisner K (2006) A review of postpartum psychosis. Journal of Women's Health, 15: 352-68.

Stein G (1982) The maternity blues. In Motherhood and Mental IIIness (eds IF Brockington, R Kumar): 119-54. Grune and Stratton.

Stuart S (2012) Interpersonal psychotherapy for postpartum depression. Clinical Psychology and Psychotherapy, 19: 134-40.

Sutter AL, Leroy V, Dallay D, et al (1997) Post-partum blues and mild depressive symptomatology at days three and five after delivery: a French cross sectional study. Journal of Affective Disorders, 44: 1-4.

Taylor A, Atkins R, Kumar R, et al (2005) A new Mother-to-Infant Bonding Scale: links with early maternal mood. Archives of Women's Mental Health, 8: 45-51.

Taylor D, Paton C, Kapur S (2009) The Maudsley Prescribing Guidelines (10th edn). Informa Healthcare.

Terp IM, Mortensen PB (1998) Post-partum psychoses. Clinical diagnoses and relative risk of admission after parturition. British Journal of Psychiatry, 172: 521-6.

Udechuku A, Nguyen T, Hill R, et al (2010) Antidepressants in pregnancy: a systematic review. Australian and New Zealand Journal of Psychiatry, 44. 978-96.

UK Teratology Information Service (2009) Use of Lithium in Pregnancy. UKTIS.

UK Teratology Information Service (2011) Use of Selective Serotonin Reuptake Inhibitors in Pregnancy. UKTIS.

Warburton W, Hertzman C, Oberlander TF (2010) A register study of the impact of stopping third trimester selective serotonin reuptake inhibitor exposure on neonatal health. Acta Psychiatrica Scandinavica, 121: $471-9$.

Warner R, Appleby L, Whitton A, et al (1996) Demographic and obstetric risk factors for postnatal psychiatric morbidity. British Journal of Psychiatry, 168: 607-11

Watanabe M, Wada K, Sakata Y, et al (2008) Maternity blues as predictor of postpartum depression: a prospective cohort study among Japanese women. Journal of Psychosomatic Obstetrics and Gynaecology, 29: 206-12

Wisner KL, Parry BL, Piontek CM (2002) Clinical practice: postpartum depression. New England Journal of Medicine, 347: 194-9.

World Health Organization (2010) International Statistical Classification of Diseases and Related Health Problems 10th Revision. WHO (http:// apps.who.int/classifications/icd10/browse/2010/en). Accessed 15 Oct 2014

\section{MCOs}

Select the single best option for each stem

1 The estimated incidence of postpartum blues is:

a $30 \%$

b $50-85 \%$

c $90 \%$

d $10-15 \%$

e $35 \%$.

2 Screening for perinatal depression can best be assisted by the:

a Hamilton Rating Scale for Depression (HRSD) b Beck Depression Inventory (BDI) c Childhood Trauma Questionnaire (CTO)

d Edinburgh Postnatal Depression Scale (EPDS)

e NEO Personality Inventory.

3 The development of perinatal depression is not significantly associated with:

a life events

b maternal age

c poor marital support

d neuroticism

e previous depressive episodes.

4 As first-line therapy for mild to moderate perinatal depression NICE recommends: a cognitive-behavioural or interpersonal therapy b pharmacotherapy

c psychodynamic psychotherapy

d solution-focused therapy

e compliance therapy.

5 Most postpartum psychotic episodes happen within:

a 8 weeks

b 1 week

c 2 weeks

d 2 days

e 1 week. 